\title{
Comparison of Methods for Postural Assessment in the Operation of Agricultural Machinery
}

\author{
Gessieli Possebom ${ }^{1}$, Airton dos Santos Alonço ${ }^{1}$, Sabrina Dalla Corte Bellochio ${ }^{1}$, Tiago Gonçalves Lopes ${ }^{1}$, \\ Dauto Pivetta Carpes ${ }^{1}$, Rafael Sobroza Becker ${ }^{1}$, Antonio Robson Moreira ${ }^{1}$, Tiago Rodrigo Francetto ${ }^{1}$, \\ Fernando Pissetti Rossato ${ }^{1} \&$ Bruno Christiano Corrêa Ruiz Zart ${ }^{1}$ \\ ${ }^{1}$ Federal University of Santa Maria, Santa Maria, RS, Brazil \\ Correspondence: Gessieli Possebom, Federal University of Santa Maria, Santa Maria, RS, Brazil. E-mail: \\ gessielip@hotmail.com
}

Received: April 23, 2018

doi:10.5539/jas.v10n9p252
Accepted: June 24, 2018 Online Published: August 15, 2018

URL: https://doi.org/10.5539/jas.v10n9p252

\begin{abstract}
The aim of this study was to perform a comparative analysis of the methods of ergonomics assessment RULA, REBA, OWAS and TOR-TOM, which the intent is to highlight similarities and differences in their use, during tillage operation with farm machinery. The study was conducted through an exploratory research in Boa Vista do Incra, RS, in August 2017, during soil preparation operation, with a tractor-subsoiler set. The operation was filmed over a period of 10 hours. After that, it was selected one hour of video, which was assumed to be representative, the video was analyzed by the methods RULA, REBA, OWAS and TOR-TOM through the software Ergolândia 5.0 and TOR-TOM, with the aid of information on noise, temperature and strength. For the comparative analyses, it was analyzed the ease of application, the importance of posture and complementary variables, and the scope of activity and postural factors. The OWAS method showed highlight in the ease of application, while the REBA and RULA methods stood out for the importance of the postural variables. For the importance of the complementary variables, RULA, followed by REBA, are worth mentioning as the most suitable. Similar results were obtained for the scope of posture factors, especially for these two methods. Regarding the scope of activity factors, the TOR-TOM obtained the most satisfactory results. Thus, the comparative analysis has highlighted the RULA method as the most suitable for postural analysis in agricultural machinery, besides the REBA method, for presenting very similar situations, contemplating full body analysis.
\end{abstract}

Keywords: ergonomics, OWAS, REBA, RULA, TOR-TOM

\section{Introduction}

The insertion of machines to replace manual labor is becoming an increasing necessity due to the increase in demand for the production of food and wood in the world. Tractors and other agricultural machines are purchased and perform most of the functions in the agricultural sector, such as land preparation, cultivation, harvesting and transportation of products (Marcon, 2013).

Whenever these scenarios are innovated, they are built to maximum safety, however, accidents can still happen. On average, 1.1 billion Reais are spent annually in benefits paid by the INSS due to the significant number of occurrences (INSS, 2017). One of the factors that deserves mention in accidents is the lack of demand from users in the insertion of safety requirements in agricultural machines, as those who buy these machines are not always the ones who operate them (Alonço, 2004).

Accidents and injuries caused by agricultural machinery were usually credited to the lack of qualified labor. However, the tractor's performance, as well as the occurrence of accidents, are far beyond these conditions. The main factors in the activities of the workers that trigger injuries or feelings of discomfort are inappropriate body postures, need for the application of force, velocity and acceleration of movement, duration, recovery time, heavy dynamic effort and localized vibration (Marques, Hallal, \& Gonçalves, 2010).

These conditions, related with environmental features such as heat, cold, light and noise, as well as additional factors such as stress, cognitive demand, work organization and workload leverage the occurrence of repetitive stress injuries (RSI) and musculoskeletal disorders related to work (Barthe et al., 2007; Skogforsk, Hallal, \& Gonçalves, 2010). 
In this sense, one of the steps of workplace ergonomic analysis is related, using ergonomic analysis methods, to assessing these potentially harmful health risk factors (Junior, 2006). There are numerous methods and techniques for the assessment of risk factors and the level of worker exposure in the workplace, ranging from simple observation techniques, to sophisticated software, which basically differ as to the ergonomic factors they consider (Santos, 2009).

Among the methods of postural analysis, RULA, REBA and OWAS are traditionally known and commonly used (Souza, 2011), while the TOR-TOM method, in turn, is presented as newer, still in search for space, but with many positive aspects (Couto, 2006). In the difficult task of choosing, the ideal method is the one which presents ease of application, making the process simple and practical; which contains the posture variables considered most important for the ergonomic analysis in that activity; besides covering the largest possible number of postural and activity factors; all this presenting a result that is simple and easy to understand (Guimarães \& Naveiro, 2004; Signori, Guimarães, \& Sampedro, 2004; Santos, 2009).

Thus, the objective of this study was to make a comparison among the methods of ergonomic assessment RULA, REBA, OWAS and TOR-TOM, seeking to disclose similarities and differences in their use, during the operation of agricultural machines.

\section{Method}

\subsection{Location and Characterization of the Study}

The study was conducted through an exploratory research at the farm Santa Helena, located at $28^{\circ} 76^{\prime} \mathrm{S}$ and $53^{\circ} 49^{\prime} \mathrm{W}$, in the city of Boa Vista do Incra, Rio Grande do Sul. Data collection was carried out in the month of August 2017, during tillage operation, with the use of a Massey Ferguson 7180 (Note 1) agricultural tractor, which was coupled to a $G T S^{1}$ subsoiler.

For the collection of data, it was performed the recording of the operation by means of a GoPro Hero 3 camera, fixed inside the tractor's cabin in a way that it was able to film the positioning of upper and lower limbs of the operator. The total shooting time of ten hours (divided into two working days) was considered satisfactory for not showing operator's behavioral changes during the operation, in addition to meeting the minimum period for postural analysis (thirty consecutive seconds), according to Striebel (2003).

For the analysis of the methods, in addition to the information in the recording, it was determined:

\subsubsection{Noise Level}

The measurement of noise level at the operator station followed the guidelines recommended by the ABNT (1987), with the positioning of the decibel meter (set with the weighting circuit A expressed in $\mathrm{dB}$ and slow response ("slow")), close to the left and right ear of the operator. Four repetitions of the measurement were collected and later determined the average among the data. Examples of studies using similar methodologies are found in forest harvesting machinery (Minette et al., 2007) and agricultural machinery (Rinaldi et al., 2008; Silva et al., 2011).

\subsubsection{Temperature}

The measurement of the temperature was performed using a WIBGET digital thermometer, model RSS-241. The temperature index was measured by placing the thermometer next to the operator station, similar to what was performed to obtain the noise values. The result, in degrees Celsius $\left({ }^{\circ} \mathrm{C}\right)$, was obtained from four replications and later determined the average among the data.

\subsubsection{Strength Required for Operating the Commands}

Initially, the controls present in the cabin were identified and characterized according to the type, in button, lever and pedals. Then, using a portable digital dynamometer, with capacity of up to $20 \mathrm{~kg}$ (model DD-200), measurements of the strength required to activate them were carried out with three replications, and subsequently it was determined the average between them. The strength was measured in the exact position where the command is located, in the required posture and the type of movement to be made, in order to simulate a real situation.

From the postural videos and additional information, the four methods of ergonomic analysis studied were applied through the Software Ergolândia and TOR-TOM, besides the conventional tables of the methods, according to Couto (2006) and Santos (2009). 


\subsection{Comparative Analysis}

The four methods of analysis studied weigh different ergonomic situations and consider different factors of activity. Thus, you cannot compare them directly (Ligeiro, 2010), however, in order to facilitate this comparison, three criteria considered important in postural analysis methods were selected (Guimarães \& Naveiro, 2004; Signori, Guimarães, \& Sampedro, 2004; Santos, 2009). They are described below:

\subsubsection{Ease of Application}

In this case, we considered three sub-criteria: the average number of calculations, the number of variables considered and the need for the consultation of tables and/or graphs, besides the number of interfaces required for the evaluation using software until the end result for analysis in agricultural machinery.

\subsubsection{The Importance of Postural Variables and Complementary Variables}

For the evaluation of the importance of variables, all possible postural positions employed by the four methods were listed and arranged hierarchically by the team from the Research and Agricultural Machinery Development Laboratory, LASERG, from the Federal University of Santa Maria, through the tool "Mudge Diagram", in order to know which, according to this analysis, are more important to be measured.

For the second step of this evaluation, concerning the postures named as complementary or additional, a table was created with the respective postures, so that in the cases where the methods had the additional item, it was added a point.

\subsubsection{Scope of Activity and Postural Factors}

For the factors of activities, in addition to the static posture aspects (Couto, 2006), stress analysis (Filho, 2006), motivational aspects (Pinheiro \& França, 2006), strength (Iida, 2005; Baumhardt, 2012), it was followed the safety attributes proposed by Alonço (2004). Once these criteria were listed, it was assigned the value 1 for the methods that covered a certain factor and 0 if the method did not cover the indicated factor.

For postural factors, it was considered the number of possible postural combinations for the methods studied, in each body segment, as well as additional positions. Factors such as activity/muscle/strength were not considered, as they were already considered in the previous analysis.

\section{Results and Discussion}

Important to note that as the aim of this study was the comparison between the methods, it was considered only their form of analysis, disregarding, in this case, the postural results presented.

\subsection{Ease of Application}

In Table 1 it is shown the subcriteria for the ease of application for the four methods. The RULA method includes nine variables (arm, forearm, wrist, wrist rotation, neck, torso, legs, muscles/activity and strength) arranged in eight tables. The method OWAS covers only four variables (upper limbs/arm, lower limbs/legs, torso and strength), arranged in three tables. The REBA method behaves very similarly to RULA with nine variables (torso, neck, legs, arm, forearm, wrist, strength, handle and muscle/activity) arranged in ten tables.

The last analyzed method, TOR-TOM, covers eleven variables to assess the operation of agricultural machinery (duration/breaks, other activities developed, energy expenditure, heat, cold, vibration, noise, confined environment, work clothes, fumes and basic posture), requiring the same number of tables for its evaluation. When analyzed by the software, the OWAS method still appears simpler, with only four analysis interfaces, followed by RULA, REBA and TOR-TOM, the latter again more complex, with a subtotal of 16 interfaces required for the analysis.

Table 1. Classification of the methods according to the criteria "Ease of Application"

\begin{tabular}{lllll}
\hline \multirow{2}{*}{ Method } & \multicolumn{3}{c}{ Subcriteria } & \multirow{2}{*}{ Total } \\
\cline { 2 - 4 } & No. of variables & No. of tables/graphs* & No. of interfaces in the software & 25 \\
\hline RULA & 9 & 8 & 8 & 28 \\
REBA & 9 & 10 & 9 & 11 \\
OWAS & 4 & 3 & 4 & 38 \\
TOR-TOM & 11 & 11 & 16 & \\
\hline
\end{tabular}

Note. ${ }^{*}$ It was considered the required number of tables and graphs to reach the final diagnosis. 


\subsubsection{Importance of Ease of Application Criteria}

The ease of use of the methods is one of the main requirements sought by applicators in ergonomic analysis (Souza, 2011). The simpler the method, the faster and practical its application is, making its applicability more attractive, as one of the major constraints on ergonomic analyses is the reduced number of assessments (Roman-Liu, 2014).

Castilho (2016) states that a method, when using diagrams of body postures, accompanied by tables that facilitate the assessment of workers' submission to the risk factors, is in advantage compared to another without the same tools. This is corroborated by Capeletti (2013), when choosing the ergonomic method considering the presence of diagrams and tables that facilitate its application.

When analyzing the general classification, it is observed that the OWAS method resulted in greater ease of application (it has a lower value), totaling eleven points, followed by methods RULA, REBA and TOR-TOM. To simplify the process of final ranking, it was assigned a decreasing value from 4 to 1 , with the highest score for the simplest and lowest score to the more complex method. Thus: OWAS (4 points), RULA ( 3 points), REBA ( 2 points) and TOR, TOM (1 point).

\subsection{Importance of the Variables}

The comparison among the twenty-three postures covered by the four methods, through Mudge diagram, classification and assignment of the degree of importance in the measurement of the postures using the methods is shown in Table 2.

Table 2. Scoring for the methods, after classification of postures in agricultural machines

\begin{tabular}{|c|c|c|c|c|c|}
\hline Posture & MD score & RULA & REBA & OWAS & TOR-TOM \\
\hline Side leaning of the torso & 11.31 & 11.31 & 11.31 & 0 & 0 \\
\hline Rotation of the torso & 10.86 & 10.86 & 10.86 & 10.86 & 0 \\
\hline Flexion of the torso & 9.98 & 9.98 & 9.98 & 9.98 & 9.98 \\
\hline Extension of the torso & 9.31 & 0 & 9.31 & 0 & 0 \\
\hline Flexion of the neck & 7.99 & 7.99 & 7.99 & 0 & 0 \\
\hline Extension of the neck & 6.22 & 6.22 & 6.22 & 0 & 0 \\
\hline Crouched or bent knees & 6.21 & 0 & 0 & 6.21 & 0 \\
\hline Flexion of the forearm & 5.54 & 5.54 & 5.54 & 0 & 0 \\
\hline Flexion of the arm & 5.32 & 5.32 & 5.32 & 0 & 0 \\
\hline Side leaning of the neck & 4.43 & 4.43 & 4.43 & 0 & 0 \\
\hline Rotation of the neck & 3.77 & 3.77 & 3.77 & 0 & 0 \\
\hline Both arms below shoulder level & 2.66 & 0 & 0 & 2.66 & 0 \\
\hline Walking or moving & 2.66 & 0 & 0 & 2.66 & 2.66 \\
\hline Extension of the arm & 2.44 & 2.44 & 2.44 & 0 & 0 \\
\hline Standing with legs straight & 2.22 & 0 & 0 & 2.22 & 2.22 \\
\hline Kneeling with one or both knees & 1.99 & 0 & 0 & 1.99 & 0 \\
\hline An arm at or above shoulder level & 1.77 & 0 & 0 & 1.77 & 0 \\
\hline Both arms at or above the shoulders & 1.55 & 0 & 0 & 1.55 & 0 \\
\hline Well supported and balanced legs and feet/well sitting & 1.33 & 1.33 & 1.33 & 1.33 & 1.33 \\
\hline Legs/feet not properly supported-badly sitting & 1.33 & 1.33 & 1.33 & 1.33 & 1.33 \\
\hline Extension of the wrist & 0.66 & 0.66 & 0.66 & 0 & 0 \\
\hline Flexion of the wrist & 0.44 & 0.44 & 0.44 & 0 & 0 \\
\hline Rotation of the wrist & 0 & 0 & 0 & 0 & 0 \\
\hline Total & & 71.62 & 80.93 & 42.56 & 17.52 \\
\hline
\end{tabular}

Note. MD: Mudge Diagram.

The REBA method stood out as the most comprehensive in this regard, followed by RULA, OWAS and TOR-TOM. Through the hierarchy process, already used in the classification of ease of application, 4 points are assigned to the REBA method, 3 points to RULA, 2 points to OWAS and 1 point to TOR-TOM. 
Table 3 presents the second step of this assessment, concerning the complementary or additional postures. For this evaluation, the RULA and REBA methods are also highlighted, totaling 6 and 5 points, respectively. The OWAS and TOR-TOM methods, for not having this possibility of complementary postures, did not score.

Table 3. Comparison of methods through complementary postures

\begin{tabular}{lllll}
\hline \multirow{2}{*}{ Description } & \multicolumn{3}{c}{ Method } \\
\cline { 2 - 5 } & RULA & REBA & OWAS & TOR-TOM \\
\hline Abduction of the arm & 1 & 0 & 0 & 0 \\
Elevated shoulder & 1 & 1 & 0 & 0 \\
Supported arm & 1 & 1 & 0 & 0 \\
Adduction of the shoulder/arm & 1 & 1 & 0 & 0 \\
Crossing of average line of the forearm & 1 & 0 & 0 & 0 \\
Deviation of the neutral line of the wrist & 1 & 1 & 0 & 0 \\
Flexed knees & 0 & 1 & 0 & $\mathbf{0}$ \\
Total & $\mathbf{6}$ & $\mathbf{5}$ & $\mathbf{0}$ & \\
\hline
\end{tabular}

In the hierarchy process, the RULA method presented 4 points, followed by REBA with 3 points and OWAS and TOR-TOM, both without scoring, assigning one point each. Posture variables, whether general or complementary, are the basis for the methods of ergonomic analysis (Ferreira, 2014), as the main factors in the worker's activities that trigger injuries or feelings of discomfort are inappropriate postures (Junior, 2006).

According to Castilho (2016), taking ergonomics beyond the study of the workplace with its characteristics and design, object placement and rhythm of activities, the posture adopted by the worker is a very important external factor. Thus, qualifying the exposure factor is considered essential in the evaluation, because without the adoption of specific postures by the employees there would be no conceptualization of the whole to be analyzed.

\subsection{Scope of Activity Factors}

Regarding the scope of activity factors, in Table 4 it is shown the results, after the comparison among the four methods studied.

Table 4. Comparison of methods by factors of activity

\begin{tabular}{|c|c|c|c|c|}
\hline Activity factors & RULA & REBA & OWAS & TOR-TOM \\
\hline Static/dynamic posture & 1 & 1 & 0 & 1 \\
\hline Stress & 0 & 0 & 0 & 0 \\
\hline Motivational aspects & 0 & 0 & 0 & 0 \\
\hline Load or strength & 1 & 1 & 1 & 0 \\
\hline Visual communication & 0 & 0 & 0 & 0 \\
\hline Dimension & 0 & 0 & 0 & 0 \\
\hline Mechanical element & 0 & 0 & 0 & 0 \\
\hline Technical manual & 0 & 0 & 0 & 0 \\
\hline Positioning and form of activation of controls and commands & 0 & 1 & 0 & 0 \\
\hline Individual protection equipment & 0 & 0 & 0 & 1 \\
\hline Stability of the equipment & 0 & 0 & 0 & 0 \\
\hline Visibility & 0 & 0 & 0 & 0 \\
\hline Noise & 0 & 0 & 0 & 1 \\
\hline Toxic substance & 0 & 0 & 0 & 1 \\
\hline Vibration & 0 & 0 & 0 & 1 \\
\hline Generating or generated power & 0 & 0 & 0 & 0 \\
\hline Qualification/Training & 0 & 0 & 0 & 0 \\
\hline Climate & 0 & 0 & 0 & 1 \\
\hline Sound communication & 0 & 0 & 0 & 0 \\
\hline Tactile communication & 0 & 0 & 0 & 0 \\
\hline Total & 2 & 3 & 1 & 6 \\
\hline
\end{tabular}


For the factors of activity, the OWAS method showed the lowest index, scoring only once, for the factor strength. The RULA method, besides also scoring in the aspect assessment of strength, scored one more point, for considering the analysis of essentially static posture. Next, the REBA method presented a total of three points, followed by TOR-TOM method, which obtained the best score with six points, for covering in its assessment essentially environmental aspects. In the hierarchy process, TOR-TOM then presents four points, followed by REBA with 3 points, RULA with 2 points and OWAS with 1 point.

In postural assessment, the factors of activity influence on employees and the work environment (de Guimarães, 2011). Besides aspects such as static posture (Couto, 2006), stress (Filho, 2006), motivational aspects (Pinheiro \& França, 2006), strength (Baumhardt, 2012), communication, qualification (Alonço, 2004), conditions associated with environmental characteristics such as heat, cold, noise and lighting leverage the occurrences of RSI/Dort's (Junior, 2006).

In the study by Ramos and Pinto (2009), the variables related to environmental comfort as noise, temperature, lighting and physical effort accounted for a considerable part of the ergonomic problems, due to the inadequate condition of the environment. Thus, the authors were able to conclude on the importance of joint analysis of posture and environment.

\subsection{Scope of Postural Factors}

In Table 5 it is presented the results to the scope of postural factors. At the end, RULA enables the combination of 3.840 normal postures and 12 combinations of additional postures, Reba 600 different combinations and 6 additional combinations, while OWAS is limited to 84 positions, and TOR-TOM, for not presenting body division analysis, including only the general postures, totals 9 possible postural combinations.

Table 5. Combination of positions covered by postural analysis methods RULA, REBA, OWAS and TOR-TOM

\begin{tabular}{|c|c|c|c|c|c|c|c|c|}
\hline \multirow{2}{*}{ Body segment } & \multicolumn{2}{|c|}{ RULA } & \multicolumn{2}{|c|}{ REBA } & \multicolumn{2}{|c|}{ OWAS } & \multicolumn{2}{|c|}{ TOR-TOM } \\
\hline & $\mathbf{N}$ & $\mathbf{A}$ & $\mathbf{N}$ & $\mathbf{A}$ & $\mathbf{N}$ & $\mathbf{A}$ & $\mathbf{N}$ & $\mathbf{A}$ \\
\hline Arm/Upper Limbs & 5 & 3 & 5 & 3 & 3 & - & - & - \\
\hline Forearm & 3 & 1 & 2 & - & - & - & - & - \\
\hline Wrist & 4 & - & 2 & 1 & - & - & - & - \\
\hline Rotation of the Wrist & 2 & 1 & - & - & - & - & - & - \\
\hline Neck & 4 & 2 & 3 & 1 & - & - & - & - \\
\hline Torso & 4 & 2 & 5 & 1 & 4 & - & - & - \\
\hline Legs & 2 & - & 2 & 2 & 7 & - & - & - \\
\hline General positions & - & - & - & - & - & - & 9 & - \\
\hline Total combinations & 3840 & 12 & 600 & 6 & 84 & - & 9 & - \\
\hline
\end{tabular}

Note. N: normal posture; A: Additional posture.

For the ranking of this sub-criterion, RULA received 4 points, followed by REBA with 3 points, OWAS with 2 points and TOR-TOM with only one point. The work postures analysis is a vitally important aspect in ensuring the health of workers in relation to possible musculoskeletal disorders (Batiz, Vergara, \& Licea, 2012), in a way that the greater the chance of possible combinations of the method, the greater the credibility assigned to it (Ligeiro, 2010).

\subsection{Final Classification of Methods}

Table 6 shows the final classification of the methods after the analyses of ease of application, importance of postural variables and scope of postural and activity factors. 
Table 6. Results of the comparison of posture analysis methods for agricultural machines

\begin{tabular}{|c|c|c|c|c|c|c|}
\hline \multirow{3}{*}{ Method } & \multicolumn{5}{|c|}{ Variables } & \multirow{3}{*}{ Total } \\
\hline & \multirow{2}{*}{ Ease of application } & \multicolumn{2}{|c|}{ Importance of the variables } & \multicolumn{2}{|c|}{ Scope of factors } & \\
\hline & & Posture & Complementary & Activity & Posture & \\
\hline RULA & 3 & 3 & 4 & 2 & 4 & 16 \\
\hline REBA & 2 & 4 & 3 & 3 & 3 & 15 \\
\hline OWAS & 4 & 2 & 1 & 1 & 2 & 10 \\
\hline TOR-TOM & 1 & 1 & 1 & 4 & 1 & 8 \\
\hline
\end{tabular}

Despite the constant use of these methods in ergonomic research, Ferreira (2014) reports that little is known about their extent and quality. The author also states that the ergonomist often faces questions about its use because there is no comparison to clarify what the appropriate method for a specific activity is. Thus, it is highlighted the importance of specifying the most appropriate method for the operation of agricultural machines.

In the final classification, the form of analysis by RULA showed the most satisfactory results, proving to be the most suitable for the postural evaluation in agricultural machines. However, the REBA method appears immediately after, also with important results. Subsequently, methods OWAS and TOR-TOM appear in third and fourth place, respectively, showing the lowest postural evaluation possibilities in agricultural machinery, for the studied conditions (Figure 1).

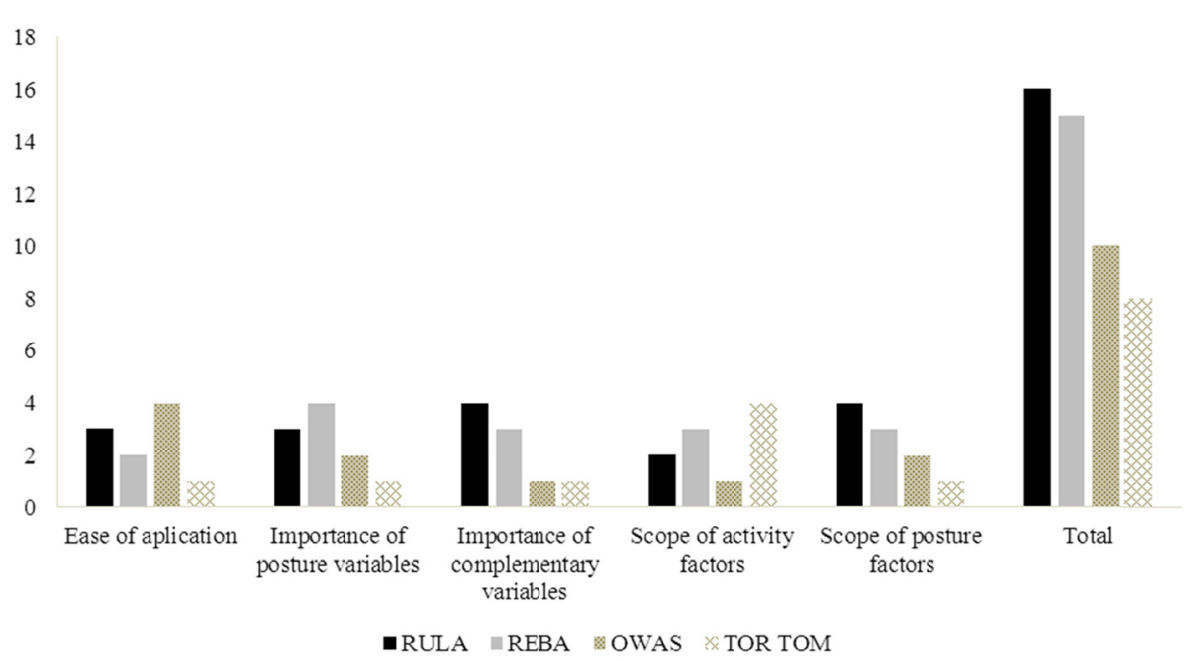

Figure 1. Comparison of postural analysis methods for agricultural machines

Despite being a singular analysis, this result confirms the evidenced by Santos (2009), who in assessing observational methods in industry also highlighted the RULA and REBA methods, and Signore; Guimarães; Sampedro (2004), in a study of two different environments, which also had for best performance the RULA method.

Even without direct comparison, the assessment by RULA also proved satisfactory in the ergonomic analysis with agricultural machines developed by Marcon (2013), having the use of this tool recommended by the author. In study by Fieldkircher (2015), comparing the results presented by three different methods of postural analysis, the author concluded that RULA is the most sensitive and therefore the most suitable for general postural analysis.

\subsection{The RULA Method}

The RULA method is considered by many as the main postural analysis method (Junior, 2006, 2009; Souza, 2011). Its high ease of application along with the use of important postural variables, make the method a target especially for analyzes involving dynamic and static postures of the torso, risks associated with upper limbs and strength (Ligeiro, 2010). 
The good performance shown by the method may be due to the main function of RULA, that is, its use in situations of sedentary tasks or where the worker is sitting or standing without walking (Mcatamney \& Corlett, 1993), such as in the operation of agricultural machines. According to Guimarães and Naveiro (2004), in a study review of ergonomics tools, RULA was the only method that allowed a classification of ergonomic problems of work environments in a sitting posture with the use of the upper limbs. The practicality allied with the ease of application of this tool, according to the authors, were the main criteria for choosing it and proof of its merits appeared in the referred study.

During part of agricultural activities, the operator has the function of directing the machine and paying attention not only to what happens in front of it, but also to the rear of the tractor, checking the operation of the implement According to Massaccesi et al. (2003), in a study of the RULA method for evaluating professional drivers, the results showed a significant association between the total values for the torso and neck and individual perception of pain in these areas, shown to be a reliable tool for the rapid assessment of load in these parts of the human body. In another study on the prevalence of symptoms in the upper limbs and risk factors, the RULA tool was successfully used, showing a clear association between the risk factors and the final value of RULA.

\subsection{The Reba Method}

The REBA method has highlights especially in the assessments of the importance of postural and complements variables. Regarding the scope of variables, the most satisfactory result in comparison to RULA and OWAS is due to the fact that the REBA method is a derivation of the two methods, specially created aiming to reduce these shortcomings in the existing methods (Hignett \& Mcatamney, 2000).

The REBA has at its core the analysis of the entire body postures, strength, load, in addition to the emphasis on the evaluation of the handle of the commands and controls, having great value still in unpredictable jobs. Unlike evidenced by RULA, it is most suitable for work done standing, exactly due the highlight given to the lower limbs (Hignett \& Mcatamney, 2000), although not failing to consider the upper limbs, torso, neck, and activity factors.

Because of its similarity to RULA and traditionalism already imposed by this method, often the REBA is replaced by the use of RULA. However, according to Shida and Bento (2012), the REBA method presents important features of division of the lower limbs in more specific segments that represent greater reliability when compared to the RULA method.

\subsection{The OWAS Method}

The OWAS method has as its main characteristic speed and simplicity (Roman-Liu, 2014), but fails in postural analysis due to the reduced number of possible postural combinations. Due precisely to this ease of application, it is presented as one of the methods most frequently mentioned in studies involving postural analysis and redesign of workplaces (Souza, 2011).

However, the OWAS method does not consider the angle of the members, resulting in a very general analysis, with low sensitivity. In its analysis, it does not cover the evaluation of the neck, wrists and forearm (very important parts in postural evaluation), factors that make the method be used strictly in less complex assessments and with lower risk (Guimarães \& Naveiro, 2004; Gómez-Galán, 2017).

In assessing the postures of agricultural tractor operators only with the OWAS method, Pauluk (2016) reproved the tool, concluding that it is a good alternative of analysis, being common to use other tools simultaneously, seeking to improve the application reliability. Taube (2002), and Peralta et al. (2010), when conducting a study using the OWAS method, increased the number of observations, besides adding a second method of analysis to reduce the error, and thus concluded for the improvement of the method after these additions.

\subsection{The TOR-TOM Method}

The TOR-TOM method is a widely used tool for analysis mainly in the industry and services sector, where the repeatability is the main feature of the activities (Couto, 2006). When applied in these conditions, it is presented as a method considered by many as efficient and complete, for covering a very considerable range of posture and operating elements (Filho, 2006). However, when it comes to activities demanding predominantly postural analysis, the TOR-TOM falls short for not deepening and considering only the basic postures. This low precision and superficiality in the analysis are portrayed as the main criticism for the methods of postural analysis (Vieira \& Kumar, 2004).

According to Souza (2011), most of the instruments do not address the cognitive and organizational dimensions of work, providing support only for the analysis of the related physical dimension, the adopted postures at work, 
the effort due to the activities of handling material, conducting repetitive movements, the design of workplaces and safety and health aspects. The TOR-TOM method, however, comprises many of the aspects of activity considered important in a method of postural analysis, however only for repetitive activities.

The same goes for the posture factor, which comprises the posture deviations only for repetitive activities (Filho, 2006). As farm machinery operation is not considered a repetitive activity, that is, there is no product or service generated or produced more than twice per minute, these aspects of the TOR-TONE cannot be considered and analyzed, making it worthless for this.

\subsection{General Analysis}

Although the RULA and REBA methods have performed satisfactorily in comparison to the others, there is still no method able to cover in detail the entire body positioning of the operator of agricultural machinery, considering angulation of upper and lower limbs, as well as relevant factors of activity and working environment. When a method is used alone, it presents limitations, such as the simplification of the information on the performed activity, and therefore, would have better application at first risk rating and not as a conclusive tool (Guimarães \& Naveiro, 2004; Signori, Guimarães, \& Sampedro, 2004, Jones et al., 2005).

In the ergonomics study performed by Castilho, Barbirato, and Sales (2016), with the RULA and OWAS tools, the results showed useful in posture evaluation, however both methods should be used in combination. Thus, it confirms the assertion by Pavani and Quelhas (2006), who mention the inexistence of an assessment tool that covers all requirements associated with occupational risks.

The risk assessment concepts in different methods can be used to develop solutions that lead to an appropriate global method for all work tasks and all parts of the body. However, it is necessary that the assumptions are verified and some standardization is introduced (Roman-Liu, 2014).

\section{Conclusions}

(1) The comparative analysis between the methods RULA, REBA, OWAS and TOR-TOM has highlighted that, for the operation of agricultural machines, the RULA method is the most suitable;

(2) The REBA method has characteristics very similar to RULA, still allowing the analysis of the whole body;

(3) Because of the ease of application, the OWAS method is most suitable in less complex, faster and larger analyses;

(4) The TOR-TOM method, although being the least indicated for the conditions studied, presents the most favorable conditions of analysis in activities of high repetition;

(5) The ease of application, the importance of posture variables and additional factors, and the scope of posture and activity factors alter the analysis of postural analysis methods, so that the most appropriate was the one that ranked more satisfactorily in these three variables, as well as in the final results shown;

(6) For the singular characteristic of each method, and in order to make the ergonomics analyses more complete, it is recommended to use more than one postural analysis tool during evaluations.

\section{References}

ABNT (Brazilian Association of Technical Standards). (1987). NBR 9999: Noise level measurement at the operator's station of tractors and agricultural machinery (p. 12). Rio de Janeiro, Brazil.

Alonço, A. dos S. (2004). Design methodology for the design of safe agricultural machinery (Doctoral Dissertation, Federal University of Santa Catarina, Florianópolis, Brazil).

Barthe, B., et al. (2007). Working at unusual times. In P. Falzon (Ed.), Ergonomia. São Paulo: Ed. Blucher.

Batiz, E. C., Vergara, L. G. L., \& Licea, O. E. A. (2012). Comparative analysis between load loading methods and postural analysis nursing auxiliaries. Produção, 22, 270-283. https://doi.org/10.1590/S0103-6513201 2005000013

Baumhardt, U. B. (2012). Methodology for the design of cabins for agricultural machines with a focus on safety and ergonomics (Doctoral dissertation, Federal University of Santa Maria, Santa Maria, Brazil).

Brito, A. B. de. (2007). Evaluation and redesign of the feller-buncher cabin based on ergonomic factors (Doctoral dissertation, Federal University of Viçosa, Viçosa, Brazil).

Capeletti, B. G. M. (2013). Application of the RULA method in the investigation of the posture adopted by a tire balancer operator in an automotive center. Monography in the specialization, Federal Technological University of Paraná, Curitiba, Brazil. 
Castilho, J. B. S., Barbirato, J. M. R. C., \& Sales, C. M. R. (2016). Postural and ergonomic analysis: Study of productive activities in a Dairy Cooperative located in the city of Itaperuna-RJ. GEPROS, 11, 39-56. https://doi.org/10.15675/gepros.v11i3.1457

Couto, H. A. (2006). TOR-TOM index: Ergonomic indicator of the effectiveness of pauses and other regulation mechanisms. Belo Horizonte.

de Guimarães, B. M., Martins, L. B., Azevedo, L. S. D., \& Andrade, M. D. A. (2011). Analysis of the workload of systems analysts and musculoskeletal disorders. Fisioterapia em Movimento, 24, 115-124. https://doi.org/ 10.1590/S0103-51502011000100013

Ferreira, A. L. R. (2014). The use of instruments of ergonomic analysis in the agricultural work process: The case of mechanized harvesting of sugarcane (Master's thesis, Federal University of São Carlos, São Carlos, Brazil).

Fieldkircher, B. E. (2015). Comparative analysis of tools for ergonomic evaluation. College Horizontina, Brazil.

Filho, G. de A. e S. (2006). Risk assessment for Ler/dort in Metallurgical company-An experience of using the TOR-TOM index and RODGERS protocol for posture evaluation (Master's thesis, Federal University of Rio Grande do Sul, Brazil).

Gómez-Galán, M., Pérezalonso, J., \& Lopezmartinez, J. (2017). Musculoskeletal disorders: OWAS review. Industrial Health, 55, 314-337. https://doi.org/10.2486/indhealth.2016-0191

Guimarães, C. P., \& Naveiro, R. M. (2004). Review of ergonomic analysis methods applied to the study of DORTs in manual assembly work. Produto \& Produção, 7, 63-75. https://doi.org/10.22456/1983-8026.1431

Hignett, S., \& Mcatamney, L. (2000). Rapid Entire Body Assessment (REBA). Applied Ergonomics, 31, $201-205$. https://doi.org/10.1016/S0003-6870(99)00039-3

Iida, I. (2005). Ergonomics: design and production. São Paulo, Edgard Blucher.

INSS (National Institute of Social Security). Social security. Retrieved December 29, 2017, from http://www.previdencia.gov.br

Jones, T., Strickfaden, M., \& Kumar, S. (2005). Physical demands analysis of occupational tasks in neighborhood pubs. Applied Ergonomics, 5, 535-545. https://doi.org/10.1016/j.apergo.2005.03.002

Junior, J. R. M. (2009). Guidelines for the use of physical workload assessment tools in ergonomics: NIOSH equation and RULA protocol (Master's thesis, Federal University of Santa Catarina, Brazil).

Junior, M. M. C. (2006). Ergonomic Assessment: Postural Assessment Methods Review. Revista Produção, 6, 133-155. https://doi.org/10.1080/10803548.2016.1156924

Ligeiro, J. (2010). Ergonomic evaluation tools in multifunctional activities: The contribution of ergonomics to the design of work environments (Master's thesis University Stadual Paulista Júlio de Mesquita, Brazil).

Marcon, L. C. (2013). Ergonomic analysis of the working conditions of agricultural tractors. University of the Far South Catarinense, Brazil.

Marques, N. R., Hallal, C. Z., \& Gonçalves, M. (2010). Biomechanical, ergonomic, and clinical features of sitting posture: A review. Fisioterapia e Pesquisa, 17, 270-276. https://doi.org/10.1590/S1809-2950201 0000300015

Massaccesi, M., Pagnotta, A., Soccetti, A., Masali, M., Masiero, C., \& Greco F. (2003). Investigations of work-related disorders in truck drivers using RULA method. Applied Ergonomics, 34, 303-307. https://doi.org/10.1016/S0003-6870(03)00052-8

Mcatamney, L., \& Corlett, N. (1993). RULA: A survey method for the investigation of work-related upper limb disorders. Applied Ergonomics, 24, 91-99. https://doi.org/10.1016/0003-6870(93)90080-S

Minette, L. J., Emília, P. da S., Amaury, P. de S., \& Kátia, R. S. (2007). Assessment of noise, light and heat levels in forest harvesting machines. Brazilian Journal of Agricultural and Environmental Engineering, 11, 664-667. https://doi.org/10.1590/S1415-43662007000600017

Pauluk, D., \& Michaloski, A. O. (2016). Ergonomic analysis of work on soil preparation activities with agricultural tractor. Revista Espacios, 37, 24-35.

Pavani, R. A., \& Quelhas, O. L. G. (2006). The evaluation of ergonomic risks as a management tool in occupational health. Annals ... XIII Production Engineering Symposium, Bauru. 
Peralta, C. B. L., et al. (2010). The study of the postures and movements in the area of boning in a beef fridge. Annals ... XVII Production Engineering Symposium, Bauru.

Pinheiro, A. K. S., \& França, M. B. A. (2006). Ergonomics applied to the anatomy and physiology of the worker (p. 165). Goiânia: AB Ed.

Ramos, M. S., \& Pinto, R. B. R. (2009). Ergonomic Analysis of the Work Environment of a dairy industry located in the Zona da Mata Mineira. Annals... IV Workshop on Ergonomic Analysis of Work, Minas Gerais.

Rinaldi, P. C. N., Haroldo, C. F., João, C. M. da S., Ronaldo, G. M. J., \& Luciano, J. M. (2008). Safety features and noise levels in agricultural tractors. Engineering in Agriculture, 16, 215-224. https://doi.org/10.13083/ 1414-3984.v16n02a09

Roman-Liu, D. (2014). Comparison of concepts in easy-to-use methods for MSD risk assessment. Applied Ergonomics, 45, 420-427. https://doi.org/10.1016/j.apergo.2013.05.010

Santos, J. M. S. dos. (2009). Development of a Method Selection Guide for Risk Analysis of Work-Related Musculoskeletal Injuries (Master's thesis, University of Minho, Brazil).

Shida, G. J., \& Bento, P. E. G. (2012). Ergonomic methods and tools that help in the analysis of work situations. Annals ... VIII National Congress of Excellence in Management.

Signori, L., Guimarães, L. B., \& Sampedro, R. M. (2004). Analysis of the instruments used to assess the occurrence of LER/DORT. Produto \& Produção, 7, 51-62. https://doi.org/10.22456/1983-8026.1418

Silva, C. B. da, Carlos, E. S. V., Luis, A. de B. A., \& Jackson, A. B. (2011). Ergonomic evaluation of a sugar cane harvester. Science and Agrotechnology, 35, 179-185. https://doi.org/10.1590/S1413-70542011000 100023

Souza, V. C. (2011). Use of ergonomic risk assessment tools: theory and practice (Master's thesis, Federal University of São Carlos, Brazil).

Taube, O. L. S. (2002). Analysis of the incidence of musculoskeletal disorders in the work of the librarian. Ergonomic considerations with a preventive approach to LER/DORT (Master's thesis, Federal University of Santa Catarina, Brazil).

Vieira, E. R., \& Kumar, S. (2004). Working postures: A literature review. Journal of Occupational Rehabilitation, 2, 143-159. https://doi.org/1053-0487/04/0600-0143/0

\section{Notes}

Note 1 . The quotation of brands and trade models does not imply any form of approval or recommendation by the author.

\section{Copyrights}

Copyright for this article is retained by the author (s), with first publication rights granted to the journal.

This is an open-access article distributed under the terms and conditions of the Creative Commons Attribution license (http://creativecommons.org/licenses/by/4.0/). 